first of our trees to clothe itself with green leaves, which are different in shape from those of our other forest trees, having five to seven leaflets, 4-9 in. long, and brilliant light green in early spring, deepening to a heavy darker shade and turning to golden yellow before they fall in early autumn.

The bark is smooth of a greenish-brown colour, and the crown generally becomes pyramidal in shape. Sometimes the branches droop, and in cases dig into the ground all round the base of the tree, whence they take root and spring up again, often attaining a much increased girth in the upward growth than that proceeding from the tree in the downward bend. A remarkable tree of this habit is in vigorous health at Hawkhurst Moor, with a height of about $90 \mathrm{ft}$., and covering the ground to a circumference of $285 \mathrm{ft}$.

The yellow horse-chestnut (Aesculus octandra). was first introduced into England in 1764. The red horsechestnut (Ae. carnea) was, according to Elwes, first introduced from Germany in 1818. Both may be seen in almost every garden and park, especially around London and other cities. Neither of these trees attains the dimensions of the common horsechestnut (Ae. hippocastanum).

Ae. pavia, a shrub bearing a red flower, is referred to by Elwes, who says "it closely resembles Aesculus octandra" and supposed to have produced with Ae. hippocastanum the hybrid Ae. carnea. Loudon describes this as "The Pavia, or smooth-fruited Horsechestnut tree" and also mentions $P$. rubra, but the whole subject is so confused that it is difficult, if not impossible, to state accurately the botanical variations.

Both the horse-chestnut and the sweet-chestnut, for some unexplained reason, are subject to spiral growth in the British Isles. During the War of 1914-18, the subject of spiral growth came very much to the fore, as apparently sitka spruce (Picea sitchensis) imported from British Columbia was found to carry this defect more than any other tree for which there was an equal demand. Inquiry into the subject brought suggestions, one of which was that it was a hereditary feature. Although this may be possible, I am more inclined to think that spiral growth is caused by the situation of the tree and its relation to the sun and wind. In Hyde Park, in the triangular piece of ground between the Magazine and the Epstein statue, by the Serpentine, there are twenty-four horse-chestnut trees, all but two of which show spiral growth, a number proportionately much greater than in any other part of the Park. 'This site must be subject to varying winds from different quarters, while the rays of the sun may influence the direction of the growth. At the same time, it is strange that one particular tree should be subject to more spiral growth than anothera subject well worth inquiry.

About 1920, shipments arrived in London, and probably Paris, Hamburg, and Rotterdam, of Japanese horse-chestnut (Aesculus turbinata-the Japanese name for which is 'Tochi-noki'). These shipments consisted of large-sized slabs, or flitches and planks. The wood was similar in colour and texture to that grown in England, but mainly consisted of highly figured wood, rich in roe and splashmottle, some bright and clean, while other was streaked with black marks-denoting incipient decay. All this timber was equally sound and good, while that streaked with black was particularly decorative, and was greatly in demand for art furniture in which it realized high values.
Speaking of the British variety, Elwes mistakenly says :

"The wood of the Horse Chestnut is one of the poorest and least valuable we have, on account of its softness and want of strength and durability. Though it has a fine close and even grain, white or yellowish-white colour, and is not liable to twist or warp so much as most woods, it does not cut cleanly."

Elwes cannot have known the many purposes for which chestnut has been used.

Quoting from "Timbers of the World" :

"If the tree be cut down early in winter, promptly sawn into boards, etc., and carefully stored, wood of extreme whiteness may be obtained. If, however, the trunks are felled later in winter, or are allowed to lie for any length of time, the wood assumes a yellowish-brown tint. It is of moderate weight, soft fine-grained, but perishable; used for making soap-bowls, brush-backs, in turnery, and occasionally for veneers. Even with the developments which have occurred since the war (1914-1918), supplies of horse chestnut are not sufficiently valued or appreciated. In Southerm Europe it is said to have been used for fruit. storing shelves; the porous nature of the wood absorbs the moisture from the fruit, the preservation of which is thereby assisted."

Besides its use for gunpowder and charcoal, the timber is most valuable for furniture and works of decorative art, for which purpose it has been by far too little appreciated.

\section{STATISTICS IN GOVERNMENT DEPARTMENTS}

A MEMORANDUM on the Post-War Organization of Statistics in Government Departments, which has been prepared by the Institution of Professional Civil Servants for submission to the Treasury, draws largely on material in the Memorandum on Official Statisties issued by the Royal Statistical Society, with the recommendations of which the Institution to a considerable extent agrees, apart from certain proposals with regard to the structure of the statistical service and the status of its officers. The Institution's own proposals are set out under five headings. First, with regard to the functions of a statistical service, it is considered that the work of the statistical service should be an integral part of the administration, including such public functions as the collection, presentation and publication of a continuous series of statistics relating to the economic and social condition of the nation; the interpretation and enlargement for publication of material already covered in part by existing statistics, together with explora. tions into fields not hitherto covered, so as to provide industry and trade with information which by its nature can only be collected through the agency of the Government; and research inta the statistical aspects of social questions. One internal function should be provision of the pre-requisites of policy formation, and the memorandum claims that the statistician, in providing material on the quantitative aspects of a probfem, should be called upon to play his part in deciding how things planned for the future are to be attained.

Next, with regard to grades, salary, promotion and superannuation of statistical staff, the Institution urges that there should be only two classes of statistician; a principal statistician class, with career value comparable with that of the administra. tive class of the Civil Service, and an executive 
statistician class, working normally under the direction of members of the principal class and with a career value comparable with that of the executive class. Superannuation should be provided on terms comparable with those available to the rest of the Civil Service, and in addition to facilities for postentry training and for opportunities for widening experience by seconding for limited periods to statistical posts outside the Government service, the Institution emphasizes the desirability of transfer of statisticians to administrative posts, as well as of transfer between departments and with the Central Statistical Office. The views of the Royal Statistical Society on the value of mechanical aids are endorsed.

With regard to the qualifications and recruitment of statistical staff, the memorandum welcomes the scheme to set up a certificate and diploma in statistics proposed by the Royal Statistical Society, and although the syllabus appears to demand a rather higher standard of mathematical statistics than would in general be required for entry into Government service, possession of the diploma is suggested as alternative qualification to a university degree with first- or second-class honours in the relevant subject, including statistics, for eligibility for appointment to the principal statistician class. For the executive statistician class, the higher school certificate with distinction in statistics, or the Royal Statistical Society's certificate is suggested. A central recruiting body for statistical officers should certify the candidate's eligibility for appointment, and appointments should be made by a selection board from eligible candidates on the basis of interview, the Board including representatives of the central recruiting body, the Establishment Department, the Institution of Professional Civil Servants and the head of the statistical section of the department concerned. These conditions are not intended to apply to existing members of the Government statistical service or to persons who have done outstanding statistical work elsewhere.

With regard to the transition to the post-war period, sufficient of the existing personnel should be retained to ensure the immediate establishment of the comprehensive statistical service envisaged, and an immediate decision on the questions of post-war organization, recruitment, salaries and promotion is a matter of urgency. With regard to statistical raw material, it is important to ensure that existing collections and compilations are preserved, and pressure from commercial firms in favour of discontmuing the making of returns necessary for statistical continuity should be resisted. Statistical branches should collect basic data from the source.

With regard to the relation between statistical branches and the Central Statistical Office, the Institution examined the suggestion for a Government statisticians' department, but decided that the type of organization recommended by the Royal Statistical Society would give a more efficient statistical service, and accepted the recommendations of the Society's memorandum with regard to the functions of the Central Statistical Office. That Office should maintain a central library and records office staffed by people competent to give advice. It should contain a full record of confidential statistics compiled by all the various Government departments, and available to authorized persons in the Government service. The library would also be the depository for statistical records of Government departments which close down.

\section{TOXIC SPRAY SUBSTANCES AND PLANT GROWTH}

NE result of the continued use of sprays containing toxic inorganic constituents may be the accumulation in the soil of substances deleterious to plant growth. Of practical interest, therefore, are experiments described by N. F. Childers ${ }^{1}$, who found that the presence of sodium arsenate in the soil had a stimulating effect on 'Delicious' apple seedlings when the concentration was not more than 20 parts per million. Between 60 and 160 parts per million, toxic effects were apparent, and if the concentration was more than 100 parts per million the seedlings died. Equivalent amounts of arsenic in the form of lead arsenate were less toxic, and lead chloride even at 160 parts per million exerted no deleterious effect. More carefully controlled experiments with plants in gravel culture showed that 20 parts of arsenic per million of culture solution stimulated the growth of apples and of rye but depressed the growth of grapes. Both apples and grapes were tolerant of 200 parts of lead per million of solution and both showed a progressive decrease in growth as the copper content of the solution rose from 10 to 30 parts per million.

Different fruits show differing tolerance of arsenic, but R. C. Linder ${ }^{2}$ reports that peaches are especially susceptible, and if the arsenic content of the leaves exceeds 2 parts per million of dry matter, marginal and interveinal burning and shot-holing of the leaves occur, with, in severe cases, defoliation. Apricots show a similar effect, but plums, pears and apples are more resistant, and plum foliage containing as much as 13 parts of arsenic per million of dry matter appeared healthy.

${ }^{1}$ Proc. Amer. Soc. Hort. Sci., 38, 157 (1941).

${ }^{2}$ Proc. Amer. Soc. Hort. Sci., 42, 275 (1943).

\section{FORTHCOMING EVENTS}

Saturday, April 28

NUTRITION Society (joint meeting with the BIOCHEMTCAI SOCIETY) (at the London School of Hygiene, Keppel Street, Gower Street, London, W.C.1), at 11 a.m.-Discussion on "The Vitamin-B Complex". INSTITUTe of PHYsICs (ELECTRONICS GRoUP) (joint meeting with the MIDLAND BRANCH) (at the University, Edmund Street, Birmingham), at 2.30 p.m.-Dr. H. Kuhn : "Atomic and Molecular Beams".

Sunday, April 29

association of austrian Gingineers, Chemists and Sotentific WORKERS IN GREAT BRITAIN (at the Austrian Centre, 69 Eton Avenue, WORKERS IN GREAT BRITAIN (at the Austrian Centre, 69 Eton Avenue, Hecent Applications of Thermo-setting Resins on Paper and Textiles".

Monday, April 30

Royal Society of ARTs (at John Adam Street, Adelphi, London, W.C.2), at i.45 p.m.-Sir Frank Smith, G.C.B., F.R.S. : "Chemicals from Petroleum" (Cantor Lectures, 3 ).

NORTH-EAST COAST INSTITUTION OF ENGINEERS AND SHIPBdILDERS (Mining Institute, Newcastle-upon-Tyne), at 6 p.m.-Sir Amos Ayre, (Mining Institute, Newcastle-upon-Tyne), at 6 p.m.- - Sir Amos Ayre,
K.B.E. : "An Approximate and Simple Formula concerning FourK.B.E. : "An Approximate and Simple Formula
Bladed Propellers of Single-Screw Cargo Ships".

Tuesday, May I

ShEFFteid METAlldorgical Association (at 198 West Street, Sheffield 1), at 6.30 p.m.-Dr. N. P. Inglis: "Some Views on Materials of Construction and their Fabrication, in the Light of Present Research and Likely Requirements".

INSTITUTION OF ELECTRIOAL ENGINEERS (LONDON STUDENTS' SECTION) (at Savoy Place, Victoria Embankment, London, W.C.2), at 7 p.m.--Discussion on the Report on "Education and Training for Engineers" and a subsequent Report on "Part-time Further Education".

\section{Wednesday, May 2}

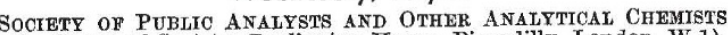
(at the Chemical Society, Burlington House, Piccadilly, London, W.1), at 5 p.m.-Mr. G. W. Osborn: "A Rapid and Simple Method for the Determination of Calcium in presence of Strontium and Barium"; Mr. W. B. Wragge: "'Lead Printing' of Ferrous and Non-Ferrous 